\title{
The Effect of Centrality Values in Urban Gentrification Development: A Case Study of Erbil City
}

\author{
Mustafa Aziz Amen ${ }^{1, *}$, Hourakhsh A. Nia ${ }^{2}$ \\ ${ }^{1}$ College of Art and Letters, Interior Design Faculty, American University of Kurdistan, Duhok, Kurdistan Region, Iraq \\ ${ }^{2}$ Department of Architecture, Alanya Hamdullah Emin Pasa University, Alanya, Antalya, Turkey
}

Received July 22, 2020; Revised August 12, 2020; Accepted August 20, 2020

\begin{abstract}
Cite This Paper in the following Citation Styles
(a): [1] Mustafa Aziz Amen, Hourakhsh A. Nia, "The Effect of Centrality Values in Urban Gentrification Development: A Case Study of Erbil City," Civil Engineering and Architecture, Vol. 8, No. 5, pp. 916 - 928, 2020. DOI: 10.13189/cea.2020.080519.
\end{abstract}

(b): Mustafa Aziz Amen, Hourakhsh A. Nia (2020). The Effect of Centrality Values in Urban Gentrification Development: A Case Study of Erbil City. Civil Engineering and Architecture, 8(5), 916- 928. DOI: 10.13189/cea.2020.080519.

Copyright $\bigcirc 2020$ by authors, all rights reserved. Authors agree that this article remains permanently open access under the terms of the Creative Commons Attribution License 4.0 International License

\begin{abstract}
Despite Erbil's citadel significant role in the urban space configuration, it suffers from many functional and accessibility problems, there is rapture in the connectivity, accessibility and visual consistency between the city precinct and the development in the peripheral area, the connectivity of the city could be increased through enhancing centrality of the urban fabric through touristic gentrification. The paper aims to find a way to increase the connectivity between the citadel and its precinct through the touristic gentrification approach. The research adopted the Urban Network Analysis (UNA) technique as a primary methodology for the analysis with its centrality principles. The methodology worked on the urban gentrification process as a way to fill the weak link to increase urban connectivity. The paper found that some areas with high connectivity values in terms of place centrality do not have an equal transformation in terms of land use and importance which accordingly, proposed to be gentrified locations.
\end{abstract}

Keywords Urban Space, Urban Network Analysis, Gentrification, Precinct, Tourism

\section{Introduction}

Cities are complex entities which composed of several parts, the different parts of cities are node, path, building, agent and boundary [1], all cities components and parts could be reduced to simple network, building and road intersection could represent the nodes while the streets represent the connection between the nodes. Accordingly, city parts are connected through spatial joints which become the most significant part in the city, however, some nodes are more important than the other in terms of their implicit centrality values, more specifically have more centrality index than other parts.

To ensure the connectivity of cities, the nodes and links should be connected and be sure that there is a continuity of the centrality spaces connecting the urban layout to avoid zones 'segregation in cities. Traditional cities might suffer from the discontinuity between their diverse parts, especially when there is a new development in the traditional center and precinct's peripheral area, consequently, such parts will suffer from discontinuity and urban fragmentation.

Hence, there is need to understand the links between cities different parts through means of centrality, especially reach centrality that represents the flow of the people between their nodes and the gravity centrality of the space which represent the intention of the urban node to attract more activities and retail through its centrality characteristics, since

"The central spaces are the most reachable spaces in the urban layout, accordingly, the reachability to determine the concentration of the space depends on the number of destinations which is connected to the central node with the reach radius" [1].

Consequently, central spaces are the best spaces to locate new activities and retail in the urban layout to connect cities' different components, accordingly, 
gentrification will be the best method to fill that gap and warrant the affluent continuity between cities' different parts.

\section{Gentrification's Definition}

Gentrification is a term used for the influx of high-income individuals in an existing metropolitan community to improve economic events, wages and land prices, and improvements in the character and culture of the neighborhood. The concept of Gentrification is a process in which members of the upper class migrate into working-class neighborhoods, displace, and alter local populations [2]. The process happens in neighborhoods that have the specific ability to transform, such as diversity and variety of the neighborhood characteristics, as well as the accessibility of the proper or affordable housing, accordingly the availability of the low-price housing and old industrial building attracts new investment and asset to old districts [3].

The gentrification process could be applied to cities with different sizes, consequently, the process is not related to some specific cities or locations, so, the experience is applied to many metropolitan and megacities all over the world, consequently cities like Ciro, Beirut, Barcelona, London, and Berlin. The urban gentrification and urban regeneration for the old cities should include the inhabitant, otherwise, it will be considered as not "Integral" and leave a gap in the urban regeneration process [4].

The objective of the urban gentrification could be reduced to four characteristics as listed below:

1. Demographics: An increase in average income.

2. Real Estate Markets: Large increases in rents and prices.

3. Transform Land Use: change land use percentage

4. Culture and historical characteristics: Novel ideas about what is attractive architecture and landscaping [4].

As a result, most of the scholars almost agree on positive impact of the gentrification process, it provides a proper solution for old neighborhoods and reduces the chance for the neighborhood's deterioration [5]. The different definitions of the word have been clarified according to the scholars in (table 1).
Table 1. The most important studies and the scholars' description of gentrification Source: The Authors

\begin{tabular}{|c|c|l|}
\hline Year & Scholars & Description of gentrification \\
\hline 1964 & Ruth Glass & $\begin{array}{l}\text { The urban renovation by transforming the } \\
\text { working class with the middle class, as } \\
\text { well as renovating the residential uses [6]. }\end{array}$ \\
\hline 1979 & Phillip Clay & $\begin{array}{l}\text { Classified and introduced different types } \\
\text { of gentrification such, as Pioneering, } \\
\text { expanding adolescents, and maturing } \\
\text { gentrification [7] }\end{array}$ \\
\hline 1979 & Neil Smith & $\begin{array}{l}\text { Reinvention of deteriorated neighborhood } \\
\text { and encouraging the middle class to move } \\
\text { by creating new opportunities through } \\
\text { reinvestment [8]. }\end{array}$ \\
\hline 1982 & Neil Smith & $\begin{array}{l}\text { Transforming land uses and moving } \\
\text { middle-class homebuyers, landlords, and } \\
\text { professional developers) to the rundown } \\
\text { neighborhoods and replacing the working } \\
\text {-class that inhabits the residential area [9]. }\end{array}$ \\
\hline Ley & $\begin{array}{l}\text { Moving different parts of social class } \\
\text { inside cities according to the sense of } \\
\text { place and promoting the urban realm [10]. }\end{array}$ \\
\hline Lees & $\begin{array}{l}\text { Transforming township and suburbs with } \\
\text { some apprehension from the } \\
\text { differentiation and changes from the } \\
\text { "myriad of forms" [11] }\end{array}$ \\
\hline
\end{tabular}

\subsection{Historical Background and Waves of Gentrification}

Glass [6] analyzed and identified the structural and social shifts that took place in certain areas of London in the 1960s, including the movement of low-income working-class people from their modest Victorian homes followed by the demolition of their residences to accommodate higher-class inhabitants in the development of luxurious suburban housing. Hence, Glass [6] realized that gentrification was a phenomenon that grew exponentially and would not deter the city or its elite [3]. Following the same line, Lees argued and defended the concept of 'geography of gentrification' that focuses on the significance of the location and locality, though both Van Criekingen and Decroly proposed a typology of various gentrification types [12]. According to the previous waves, gentrification grew with the districts and had an impact on protecting the developed neighborhood from deteriorating and declining, the different waves with their descriptions are clarified in table 2, where it is clear how each wave stated and worked to modify the different part of the London city. 
Table 2. Waves of Gentrification: Source the Authors

\begin{tabular}{|c|c|c|}
\hline wave & Time & Description \\
\hline First Wave & 1950- 1973 & $\begin{array}{ll}\text { - } & \text { Transform the working class with new urban "gentry". } \\
\text { - } & \text { Modify the old neighborhood with middle-class people [13]. }\end{array}$ \\
\hline Second Wave & 1970s. & $\begin{array}{l}\text { - Encourage cultural solutions and create integration between gentrification and new uses like } \\
\text { art galleries, museums, and historical preservation [14]. } \\
\text { Endorse and encourage integration with financial support from financial institutions and } \\
\text { banks, so the whole process started to attract real estate developers and banking finance. }\end{array}$ \\
\hline The Third Wave & $1990 \mathrm{~s}$ & $\begin{array}{l}\text { - The gentrification process becomes a comprehensive process starting from the neighborhood } \\
\text { centers to the outward parts in an all-inclusive way. } \\
\text { - The gentrification process started to include mega-scale projects and developers. } \\
\text { Increment of the gentrification process as the resistance of the process became less and } \\
\text { meager as a result of the continuous movement of the lower class and the workers from the } \\
\text { center to the other part of the city [15]. }\end{array}$ \\
\hline
\end{tabular}

\subsection{Gentrification and Tourism}

Tourism is the invention of local cultures and historical differences which is compatible and comes close to the visitor's tastes [3], similarly, the tourism is one of the most significant industries that normally get the support and the backing from the entertainment companies and hotels firms all over the world with a wide range of brand cooperation to renovate a local area into spaces for attracting and consumption [16]. As a result, the tourism industry has a vital effect on cities, nevertheless the traditional parts in cities' centers which contain cities' traditional area and heritage that needs to be dealt with [17]. Thus, it is logical to provide gentrification locations in the tourism area because those places have the internal influence and effect over all the cities' different parts, however, the gentrification area with tourism work well in case of combining those variables with the centrality values of the urban layout.

\subsection{The Impact of Tourism on City}

People practiced tourism industry from a long time, cities have been getting people and visitors for a long time, but, tourism as an urban development approach and direction started to appear and emerge at the beginning of 1990, accordingly scholars started to think about the tourism approach for the urban renovation and regeneration [18]. The concertation of studies on cities' centers and traditional area makes the scholars forge another word to explain the process that leads to change the urban from and activities in cities' central parts, the word is "touristification" which is a direct reflection of the demand and understanding of the need to explain the procedure of alteration in urban forms [19]. The procedure had a specific consequence on the "tourist-historic city" whose main purpose is to understand the reflection and the interaction between the place, visitors, and the different activities in the place [17].

The Touristification approach has a many-fold interests and approaches, these include studying the impact of the "destination sites" on the tourism industry, which some scholars called the holistic approach [20]. Similarly some approaches focus on the economic impact as a major force to attract people and visitors to the destination [21], while some other approaches concentrate on the "events" as the main force in the tourism process such as European Capital of Culture, the attitudes of residents to tourism development issues, that impact the overcrowding perception and experience [22,23], similarly, some approaches focus on alterations in the commercial landscape resulting from the development in tourism [17], finally, there is the social approach which concentrates on the social impact of the tourism with the interaction between the inhabitants and the visitors in the destination area [24].

Since tourism development depends on several values, there is a need to enforce the most important values that regulate the tourism industry, those values are the destination's characteristics and the number of visitors. Accordingly, those values create an economic, social and physical change and alteration to the place, yet, it is not an obligation to get always positive results following the availability of the previous values which means that sometimes the effect might be positive, while some other time the impact will be negative. Thus, for implementing sustainable development and planning in the starting point, there is a vital need to minimize the negative properties and maximize the positive properties of tourism [25]. Many studies suggest that to achieve a proper and sustainable tourism development, there is a need to understand the connection between the different components of the urban realm such as shared economic necessity and the population, the closeness of the home address or the residential area to the places with high visitors' number [26], yet, the high number of the visitors leads to overcrowding in the destination place [27], which allows conflicts, alliances, paradox and contradictions to be identified through areas of interest and reference scales [28]. As a result, the urban tourism could provide a significant effect on the urban form, from one side it has a major effect on the urban economics, from the other side it has a significant role in connecting cities different parts, in another word it provides the "Flow" that represents the way that people permeate and flow between the different parts of cities, however, those flows are attached to the 
central location in cities in term of the central places, which are the best location of the urban gentrification.

\subsection{Tourism Gentrification}

Tourism gentrification is an urban approach starting to appear within the last fifteen years [29], it first appeared in Gotham's article on the Vieux Carré (French Quarter) in New Orleans [17]. The concept of the urban tourism is elated to different urban development approaches; accordingly, it is related to the role of local authorities, the growth in urban tourism, connection with property promotion, public urban regeneration, a residential displacement that include evacuating an area and changing the previous uses and settler with people that have more spending power and commercial gentrification [17].

The concept and approach of "tourism gentrification" as an experiential tool to explore and explain the alteration and transformation of a neighborhood of middle-class into a comparatively prosperous and high-class territory that incline to increase the propagation of commercial entertainment and tourism venues, this transformation leads to what some scholars call "chaotic concept" [11]. Scholars asserted that there are two types of tourism gentrification according to the nature of the development, the first approach is a twin process that combines the globalization and localization that outline contemporary urbanization and renovation processes, while the second approach provides a real challenge to the traditional understanding of tourism gentrification in terms of demand-side or production-side factors driving the process. However, some scholars see the process "as part and parcel of the class dynamics of urban transformation associated with capital investment and disinvestment" [30], or "highly visual expression of changing patterns of consumption in cities" [31].

The most significant part of the tourism gentrification is the concentration on the effect and impact that process gentrification in the destination place, accordingly the place itself with its physical characteristics has a great role on the urban development, so, all the physical characteristics, like the urban form and the urban layout will play a big role in the whole gentrification process, in addition to the generated effect on the community.

Hence, the plots price, residential displacement, the right to housing, loss of local traders, etc., will be a part of the tourism generation [32]. However, residential displacement is determined by tourism gentrification and revitalization policies which affect not just the neighborhood under gentrification, rather the effect would extend to several adjunct neighborhoods, particularly by the growing transformation of functions and uses [33].

\subsection{Commercial Gentrification as Indirect Displacement}

In the process of gentrification, there is a displacement of old activities that would be replaced by new ones, numerous writers focused on Marcuse's conceptualization that distinguishes between 'indirect displacement' and "direct displacement" [34], accordingly, 'direct displacement' refers to and denotes the transform and move the original inhabitants from the destination neighborhood, while, the other method is 'indirect displacement' which is a long-term approach and process that force the low -income people to move from districts or destinations' neighborhood according to continuous pressure on them from the developers [35].

It is worth to mention that the commercial activities are the main force to transform area and make gentrification possible through the continuous pressure that influences the neighborhoods life and makes the alteration in the area structure, accordingly attracts more people to the area from one side and impacts the original people to leave the area gradually for wealthy people that can invest more in the area and looking for more silent and appropriate space. The gentrification literature identified the direct and indirect movements and displacement pressures, these forces, and pressures are well-defined below.

A. Lack of consumption facilities: the main goal of this approach relates to the incapability of low -income inhabitants to stay in their area as a result of the loss of stores and facilities, accordingly these people will be displaced by upper-income people gradually, it is worth to mention that the main force that plays the significant role in this process is the commercial gentrification [36].

B. Economic pressures: this one also depends on the commercial factors as the main force to transform the area in term of "affordability difficulties" [37], which means that neighborhoods are not able to provide affordable service within its boundaries, accordingly the inhabitant will start to leave such area because of the lack of the main affordable service and look for another place, as a result, new move of services and facilities start to move to the area and transform the main functions and uses.

C. Cultural pressures: this is related to the transformation of the land use according to the lifestyle's characteristic, so there will be new forms of consumptions that work as generators to attract people to the new district [36].

D. The privatization of public space: This approach is related to transform the management of public space to private management and ownerships, accordingly, the public and communal area in the neighborhood could be privatized in term of the management by long term rent, thus it could be transformed to café and restaurant and entertainment area, however, this process will include the removal of the public facilities and benches [38] and dismissal of informal dealers [39]. These approaches of indirect displacement movements and pressures are not 
working independently, but as mutual foundations that pressure the measurements of low-income inhabitants to continue in the neighborhood's gentrifications [35].

\subsection{Conclusion}

Gentrification is the best way to increase cities productivities and enhance its social and economic values, however, the gentrified location must be located in the best central location in cities' urban layout. The central places serve cities in two ways, first, it links cities' different components and ensures the flow between different parts, secondly, it increases cities comprehension through tourism gentrification as it clarifies in figure 1

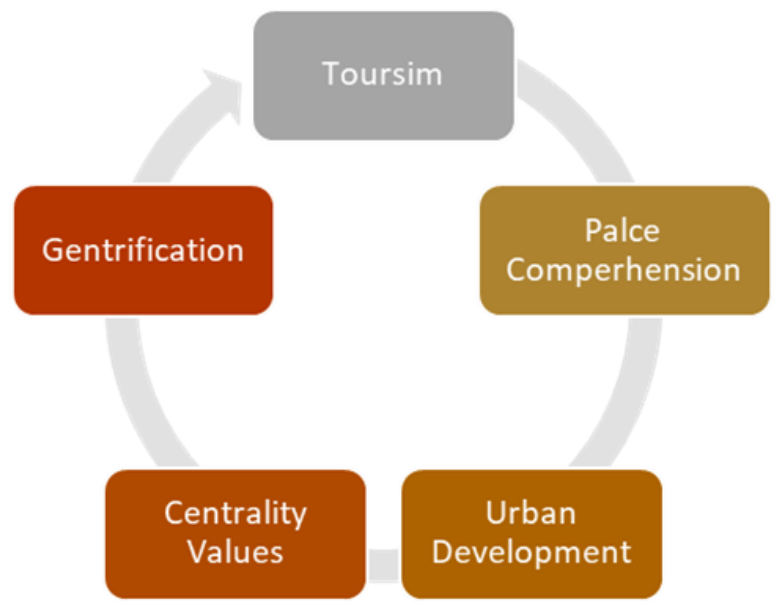

Figure 1. Urban Development process through Gentrification

\section{The Methodology}

The urban layout composed of five main parts, those parts are the nodes (intersection), paths (street segment), buildings, boundaries, and agents, all those parts work together to create the urban built form [1], those parts are the most significant components that affect cities' centralities layout parts [40]. Accordingly, any spatial network analysis for the urban layout should take into consideration the urban components to find a proper explanation for the urban reality and better understand the urban concentrated locations. As a result, the paper adopted Urban Network Analysis(UNA) to find reach and gravity's centrality attributes to estimate the gentrified plots locations within the city, the method focuses on cities' buildings, which accommodate activities, consequently where most urban activities and trips begin and end [41], as a result, the method takes into account the existing of the buildings as a third factor in creating cities graph network in addition to the edges and nodes of the street network, which flow between buildings.

The classic method of graph representations composed of nodes and edges only, ignoring the significant importance of the variations that result from the inbuilt land-use distribution and density that formulate and characterize the environments and the urban layout [42]. However, the buildings' locations which represent the positions of the most of the urban activities are missing in the classic representation of the urban layout analysis, accordingly one of the urban components is missing in the layout analysis, therefore, there is a need to add the missing part and represent the buildings in the analysis in addition to the network intersections that represent the street junction [41].

Although the buildings could be represented as nodes in the spatial analysis, the question remained whether there is an extra characteristic that should be added to the building nodes, although most urban graph representations to date have been used in the unweighted form [41], there is a need to add weights to the buildings in the spatial layout [1], as a result, the spatial network analysis should be represented through the participation of the four components those are the street segments (edge), street intersection (node), building (node), the boundary of the neighborhood ( the study area), taking in the consideration that the weights could be added to any of the above mentioned components, yet it could be added to the components' characteristics, but we believe that the weight issue is far from the scope of this paper and that we used an unweighted network for the sake of the analysis of the current paper. For the sake of the paper, the authors used Esri ArcGIS v. 10.6 with urban network analysis plugins to commend all the analysis, an extra software of IBM SPSS v. 25 used for analyzing the research data and performing the required statistical analysis.

\subsection{Reachability to the Urban Nodes}

Reach plays a significant role in indicating the most accessible place in the urban fabric as it represents the places with the most accessibility area in the urban fabric, accordingly, the nodes reach centrality in a spatial graph designates the number of other nodes that are accessible and reachable from at the shortest path distance of at most, in our case will represent through two parts the first one is the buildings while the other part is the intersection or the junctions between the streets in the urban spatial layout. The mathematical equation of the reach centrality is defined in equation 1 :

$$
\operatorname{Reach}[i]=\sum_{j \in G-\{i\}, d[i, j] \leq r} W[j]
$$

Where $d[i, j]$ is the shortest distance of the path between nodes, the nodes represent the buildings' location, W represents the proposed weight of destination nodes [41]. For the sake of this paper, we suggested declaring $\mathrm{W}=1$ for all the nodes in the case study boundary area. Accordingly, all the nodes, more specifically all the building will share the same weights for the spatial layout analysis. 


\subsection{The Gravity of the Urban Nodes}

Gravity centrality measures influences in the spatial impedance that required to travel to each of the destinations, first introduced by Hansen (1959), Gravity index is one of the most prevalent measures for the spatial accessibility in transportation research. Accordingly, the index represents high accessibility when the index is close to the high number of close to 1 in case of normalizing gravity, or averaging the index values as the mean maximum Gravity (MMG) for the block. However, due to the exponential distance decay, scholars found out that trips do not significantly contribute to the gravity index beyond a certain distance [43].

The Gravity centrality index adopts that accessibility at a location or a building is relative to the attractiveness (weight) of destinations surrounding and inversely proportional to the distances between them as it is clarified in equations 2 and 3 [41].

$$
\begin{gathered}
{[\mathrm{i}]=\sum} \\
{[i]=\sum \sum_{-\{i\}, d[i, j] \leq} \frac{}{d[i, j]}} \\
-\frac{W[i, j] \leq}{d[i, j]}
\end{gathered}
$$

The equation 2 and 3 are different in term of the weight of the node attractiveness which could be defined through the weight of the place, accordingly, if there is no weight attributed to the destination node then the general weight will be equal to 1 , however, the gravity centrality index will exactly equal reach centrality index in case that the beta value in the equation was equal to zero, similarly, if the buildings are weighted, then the Gravity index is directly proportional to the weight of each of the other buildings that can be reached within the given search radius [41].

\section{The Case Study of Erbil's Precinct}

The paper aims to find the best gentrification places in the study area in the Erbil precinct, and the gentrified area should be located in the most appropriate central area in the urban spatial layout in term of reach and gravity centrality. The studied area is within the diameter called the 60-meter street in Erbil's city, which is the area defined between the citadel in the center and the 60-meter street (Shasti), which is the boundary of the case study (Figure 2). The paper adopted the accessibility as a strategy to achieve the previous goals; accordingly, the central area will be the most appropriate location that provides optimum solutions.

The researcher studied the people's accessibility to each plot or building within the studied area, accordingly, to find reach and gravity's centrality values. After defining the boundary which is one of the urban components, the papers used the other three components of the urban layout by converting them to path and nodes that interact together in the urban spatial analysis.

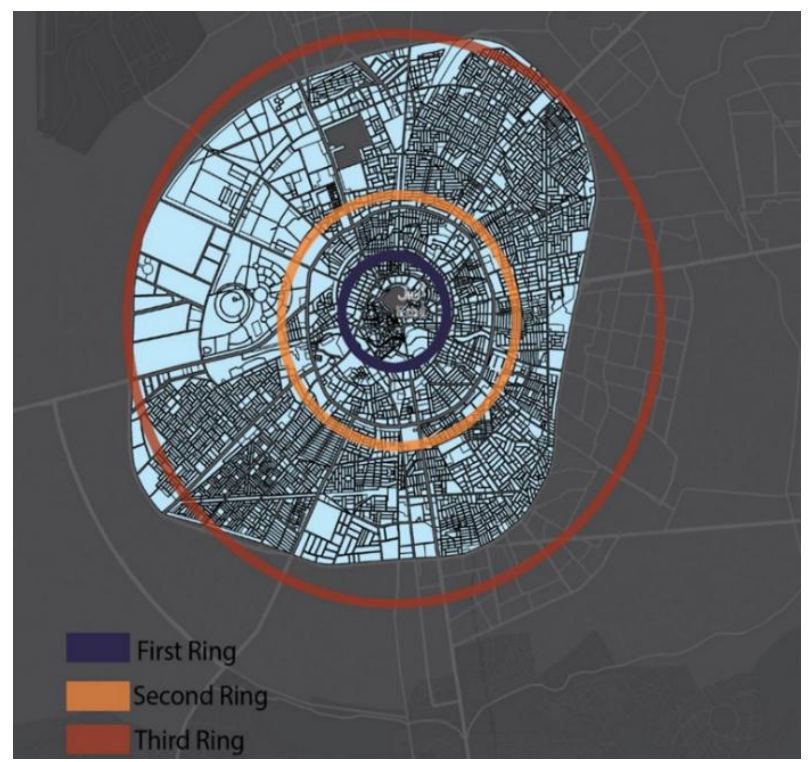

Figure 2. The studied area, the yellow line defines the boundaries of the reach and gravity calculation, while the blue lines defined the citadel precinct. Source: The Authors

The first part deal with the buildings in the spatial layout which is transformed to polygons that defined by the plots' boundary and limits, hence, polygons define the boundary of each plot with the studied urban fabric, each polygon represents one building or plot connects to the path in the front of the plot, so, the path will have more connection when it gets to have more buildings or plots. The researchers proposed that each building has a direct effect on the total gravity of the layout, accordingly gravity power will increase according to the number of the buildings within the layout which means that the centrality values for the spatial layout increase rapidly the buildings increment.

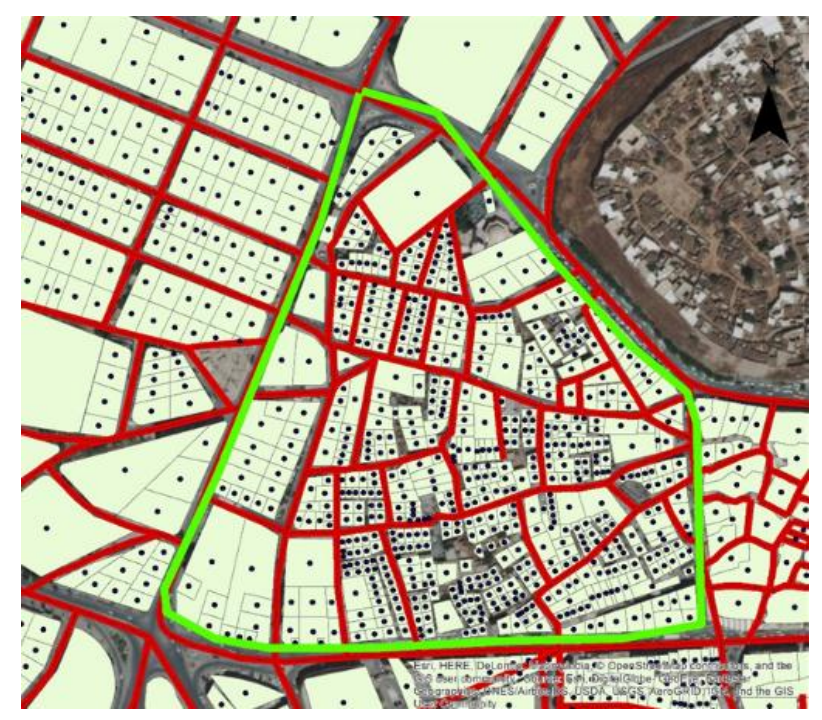

Figure 3. The study area with building boundaries represented as polygons, a system of road networks as lines and the locations of the buildings as points

The second and third parts deal with the urban network 
which is the result of the nodes that represents that streets intersection and the path which is the distance between two nodes in the spatial layout. Consequently, the whole network represented by edges, so the edges of the paths represented by a fine network signify the whole accessibility networks of streets. Hence, it is clear that the research is looking for the physical urban characteristics that do change the working capability and ability of the urban layout to accept new challenges and uses in the urban realm, accordingly to work properly with new uses that could be inserted as primary requirement of the urban touristic gentrification. The research methodology of defining nodes and the paths in the urban layout are clarified in figure 3 .

The research used the reach and gravity equations for calculating the accessibility values for each plot in the site. The final output of the calculation is clarified in figure 4 and figure 5 .

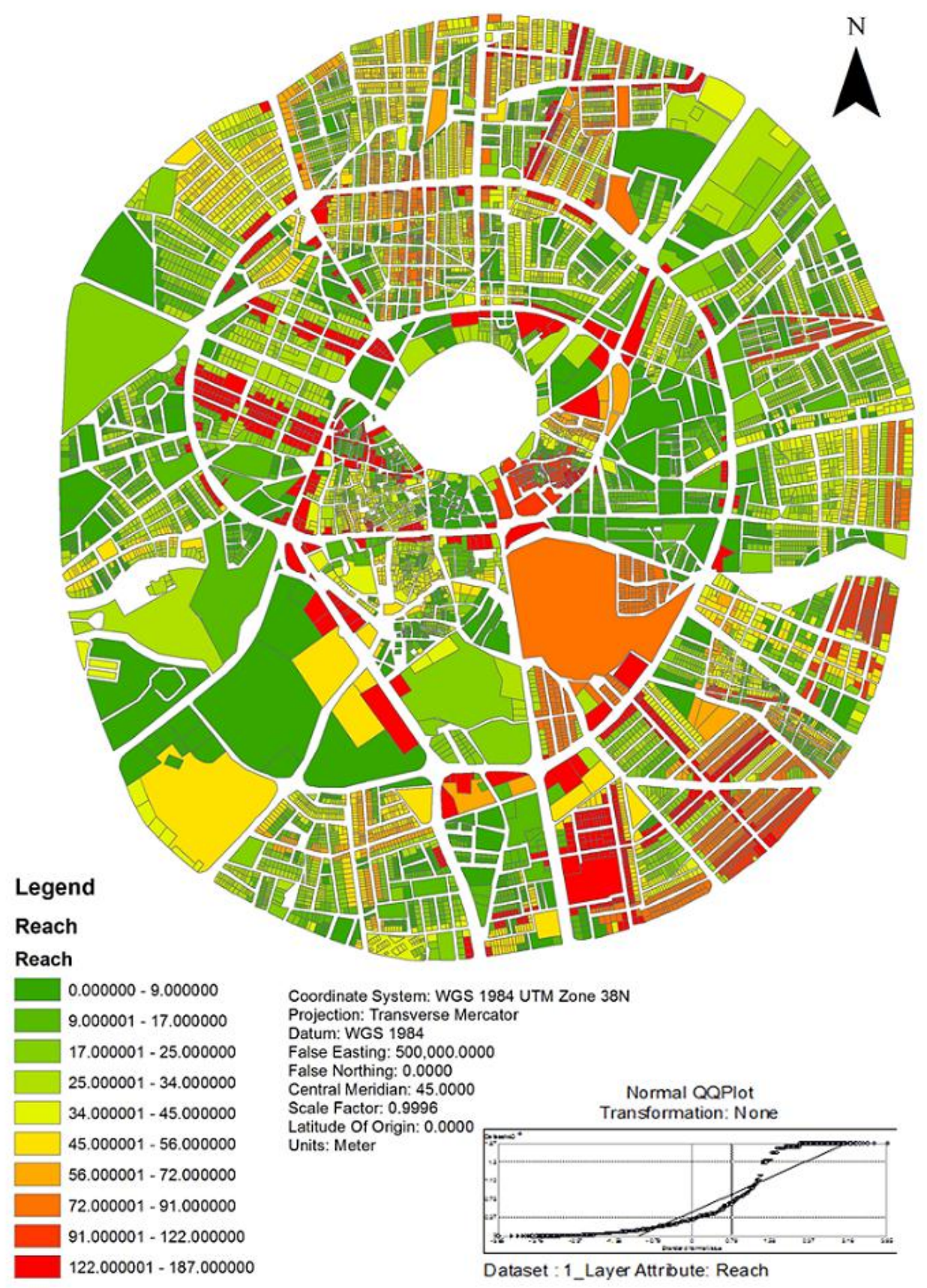

Figure 4. Reach of each plot with the graph of the studied area, the red color represents the powerful one while the green is the weak one. Also, the QQ plot clarify the distribution of the reach attribute through the city 


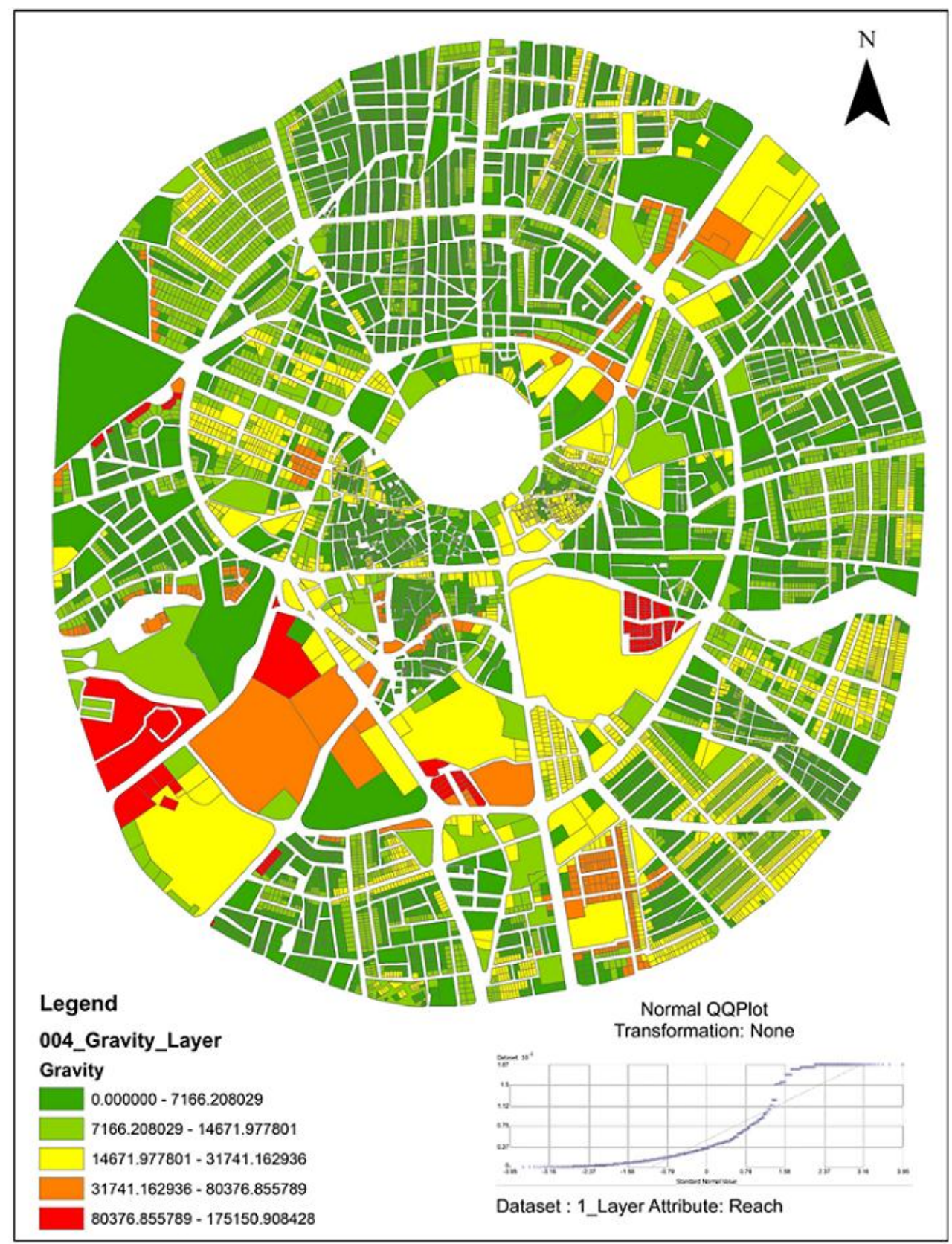

Figure 5. Gravity of each plot with the graph of the studied area

As it is shown in figure 4, the maximum reach attribute is within the range (122-187) and the minimum is (0-9). Also, the results show that the distribution of the reach within the studied area is not normal as shown in the Q-Q plot, therefore, it is worth mention that the citadel precinct has a powerful reach attribute with a network that has implicit accessibility power (red plots). Similarly, the studied area has many plots with a highly reachable attribute, but unfortunately, most of those spaces and plots have been used as parking or garbage area within the precinct which needs to reconsider those locations and reuse those spaces with highly efficient new uses that serve the touristic gentrification strategy and process. The research used the reach values as an index for the weight attribute in the gravity model with a $\beta$ value which is specified for pedestrian, as a result, the maximum gravity values is within the range (12999-22001) and the minimum is $(0-404)$.

However, it is worth mentioning that the citadel precinct has a powerful reach value within the urban spatial network, but, that value is less important when it come close to the citadel itself, which means the centrality connection in term of reach is less important in those places. As a result, those spaces need to be reconsidered in term of spatial layout uses and distributions to avoid cutting off the network centrality connections. Also, the studied area has many plots with a highly reachable attribute, but unfortunately, most of those spaces and plots work as parking or garbage area within the precinct. The researchers used the reach values as an index for the weight 
attribute in the gravity model with a $\beta$ specified for the pedestrian. The maximum Gravity attribute (figure 4 ) is within the range (12999-22001) and the minimum is $(0-404)$. Also, the results show that the distribution of the Gravity within the studied area is not normal as it is shown in the Q-Q plot. According to the findings the citadel precinct has many spaces with high gravity attributes, especially in the studied area. Unfortunately, most of the spaces with high gravity attribute in the studied area are used for parking, storage, and a place for collecting garbage.
It is worth mentioning that the gravity and reach attributes of the plots increases in the central area as it is clarified in figure 5. A large number of the spaces with highly gravity attributes locate in the area within the citadel precinct; those plots have high connectivity properties with small size area comparing with the other parts of the city. Also, the research showed that the correlation between reach and gravity centrality values are significant with correlation coefficient 0.9 (Table 3) and coefficient of determination equal to 0.813 (Figure 6).

Table 3. Shows the correlation between the different attributes used in the analysis of the studied area

\begin{tabular}{|c|c|c|c|c|c|}
\hline \multicolumn{6}{|c|}{ Correlations } \\
\hline & & Reach & Straightens & Gravity & Shape_Area \\
\hline \multirow{3}{*}{ Reach } & Pearson Correlation & 1 & $.955^{* *}$ & $.902 * *$ & -.015 \\
\hline & Sig. (2-tailed) & & .000 & .000 & .085 \\
\hline & $\mathrm{N}$ & 12770 & 12770 & 12770 & 12770 \\
\hline \multirow{3}{*}{ Straightens } & Pearson Correlation & $.955^{* *}$ & 1 & $.904 * *$ & -.009 \\
\hline & Sig. (2-tailed) & .000 & & .000 & .291 \\
\hline & $\mathrm{N}$ & 12770 & 12770 & 12770 & 12770 \\
\hline \multirow{3}{*}{ Gravity } & Pearson Correlation & $.902 * *$ & $.904 * *$ & 1 & $-.022 *$ \\
\hline & Sig. (2-tailed) & .000 & .000 & & .014 \\
\hline & $\mathrm{N}$ & 12770 & 12770 & 12770 & 12770 \\
\hline \multirow{3}{*}{ Shape_Area } & Pearson Correlation & -.015 & -.009 & $-.022 *$ & 1 \\
\hline & Sig. (2-tailed) & .085 & .291 & .014 & \\
\hline & $\mathrm{N}$ & 12770 & 12770 & 12770 & 12770 \\
\hline
\end{tabular}

**. Correlation is significant at the 0.01 level (2-tailed)

*. Correlation is significant at the 0.05 level (2-tailed)

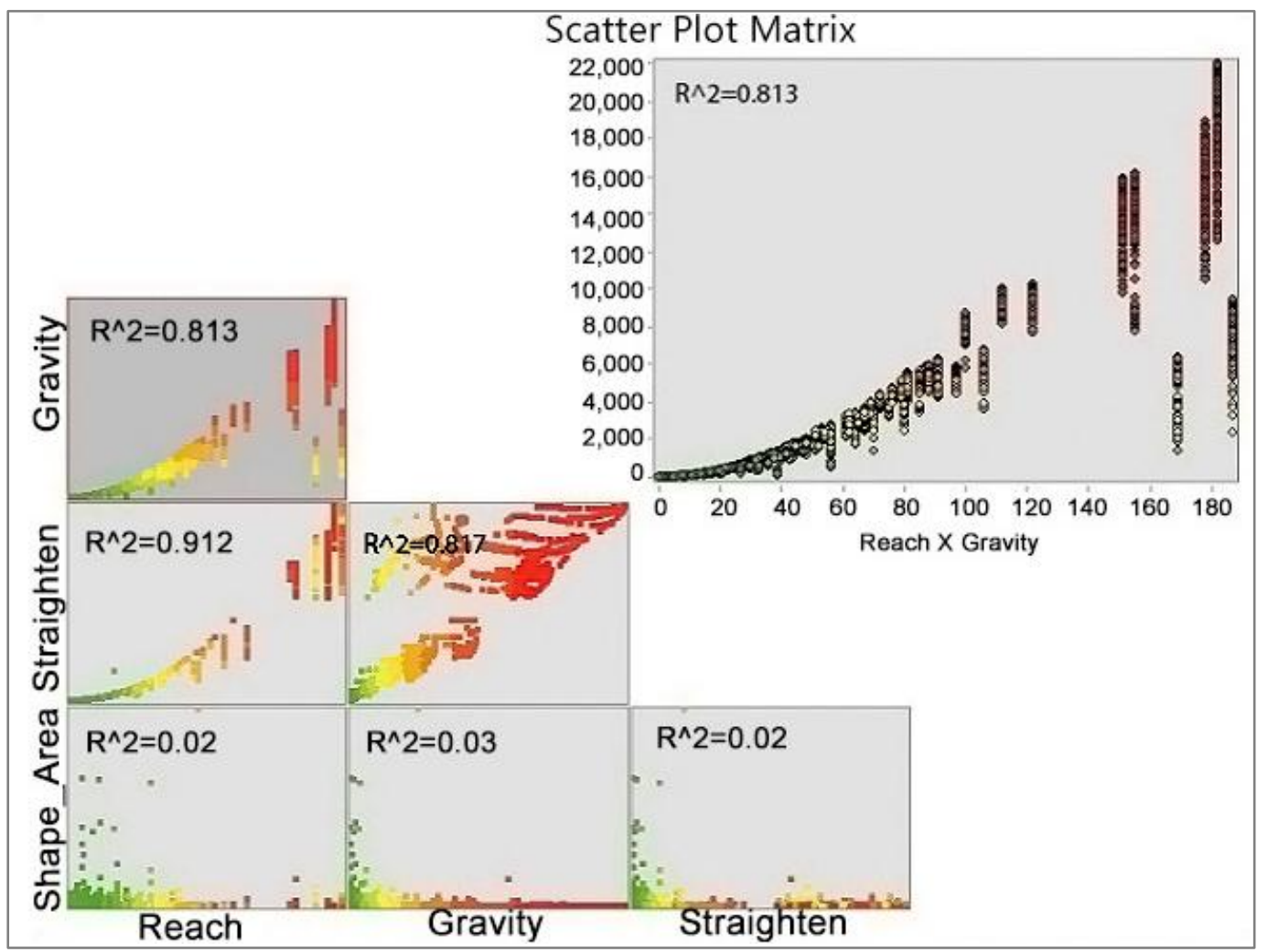

Figure 6. Radial distribution of gravity according to the radial distance 
Most of the plots and buildings that have a powerful reach, gravity and correlation are located within the precinct area, which is the result of the dense buildings and incrementally successive small plots size, so that area is defined with high reach and gravity values which is essential for pedestrian, inhabitants, and visitors to be recognized the urban realm and build their mental image about the urban spatial layout.

The reachable plots and building play a significant role in the urban space configuration as studies on cognitive maps and urban travel found that people's cognition is affected by urban configuration [44], therefore the research worked on the plots which have the most significant power in term of reach and gravity to be used in the gentrification policy for developing the area within the precinct area, to create a cognitive mapping [44].

Although some researchers insist that there is a strong correlation between the plot area and the accessibility, where the small plots are more accessible than the small one. The research showed that there is no significant correlation between the reach and shape area, according to the analysis there is no significant correlation between the reach the shape area which is just -0.015 correlation. There are two reasons for that result the first one is related to the reach mechanism and the second one related to the assessed nodes and locations which are considered all to have the same spatial weights. However, the analysis showed that the correlation between the gravity and reach area is significant at the 0.05 level, which is the result of the $\beta$ value that adds excessive value to the gravity calculation because it is related to the people ability to surf the urban realm and understand the urban spatial layout.

\section{Conclusions}

Giving to the literature, most of the developed methods of the gentrification process depend on altering and changing the urban land use according to the requirement of the gentrification, however, the urban gentrification methods didn't show how to do the change process, most significantly, how to select the gentrifications' location? or where is the location of the gentrification nodes?

According to the finding, the studied area is full of plots and buildings with high reachability and gravity, places that have the initiatives to be best gentrified places, but most of the accessible spaces are abandoned or used as parking lots, at the same time, the land values in the area are too high which is not proportional to the current land use, and represents an economic failure in term of land use and efficiency. However, most of those spaces could be used in the gentrification process for developing the area. The researchers believe that those spaces with high degrees of gravity are the best places to locate new gentrified function in the studied area that could increase the connectivity of the urban layout as it is clarified in figure 7 .

The analysis showed that the area around the citadel which is supposed to have the most powerful ability in term of reach and gravity centrality doesn't play a significant role in connecting the urban layout. The reason for that weakness lies in the fact that each plot within the ring around the citadel takes the power of the reach and gravity from one side while the other side is disconnected because of the existing of the citadel. Accordingly, there is no continuous connection because of the differentiation in the level.

\section{Recommendations}

The research recommends adopting the spatial analysis, especially the analysis based on the reach and the gravity to understand the best location or connection between the traditional places and its precinct, especially when there is the intention to develop that area for tourism engorgement. Also, there is a need to make more inventions in adding weights to the spatial nodes that connect the urban layout physical network because that weight might affect the spatial interaction between the connected nodes and as a result affect the whole urban layout.

Also, the research recommends studying the urban layout of the cities and finds a proper weighting system to measure the weights of the urban components in terms of the type, accordingly, there will be the weight that is specified for the edges, weight for the nodes, and weight for the boundaries. It is important to consider the differentiation between the weight of different types because the characteristics of the components differ in a wide range.

As well as, the research recommends reducing the traffic accessibility in the area with high reachability and gravity centrality index, as a result, the central area will be dedicated to the pedestrian rather than vehicles. The transformation of the area in this way will increase the walkability of the city, as a result, increase the connectivity of the different parts of the city which is a significant factor in creating a sustainable city.

Also, giving that the plot with highly gravity attribute should be allocated to the gentrification function, the process of gentrification should use some part within the citadel precinct to create an axis line between the precinct and the plots outside the precinct so the feeding of the area will continue smoothly and increase the accessibility of the site from the boundary of the 60-meter road.

Lastly, In the process of developing the studied area, there is a need to keep the number of gravities in its current rate or increase the number of buildings as this will increase the reach rate that proportionally increases the accessibility of the node in the studied urban fabric, for the development of such area which locates in the precinct, there will be a need to develop roots to increase the connectivity of the area with the other parts in the city, especially with new urban fabric as it is clarified in figure 7. 


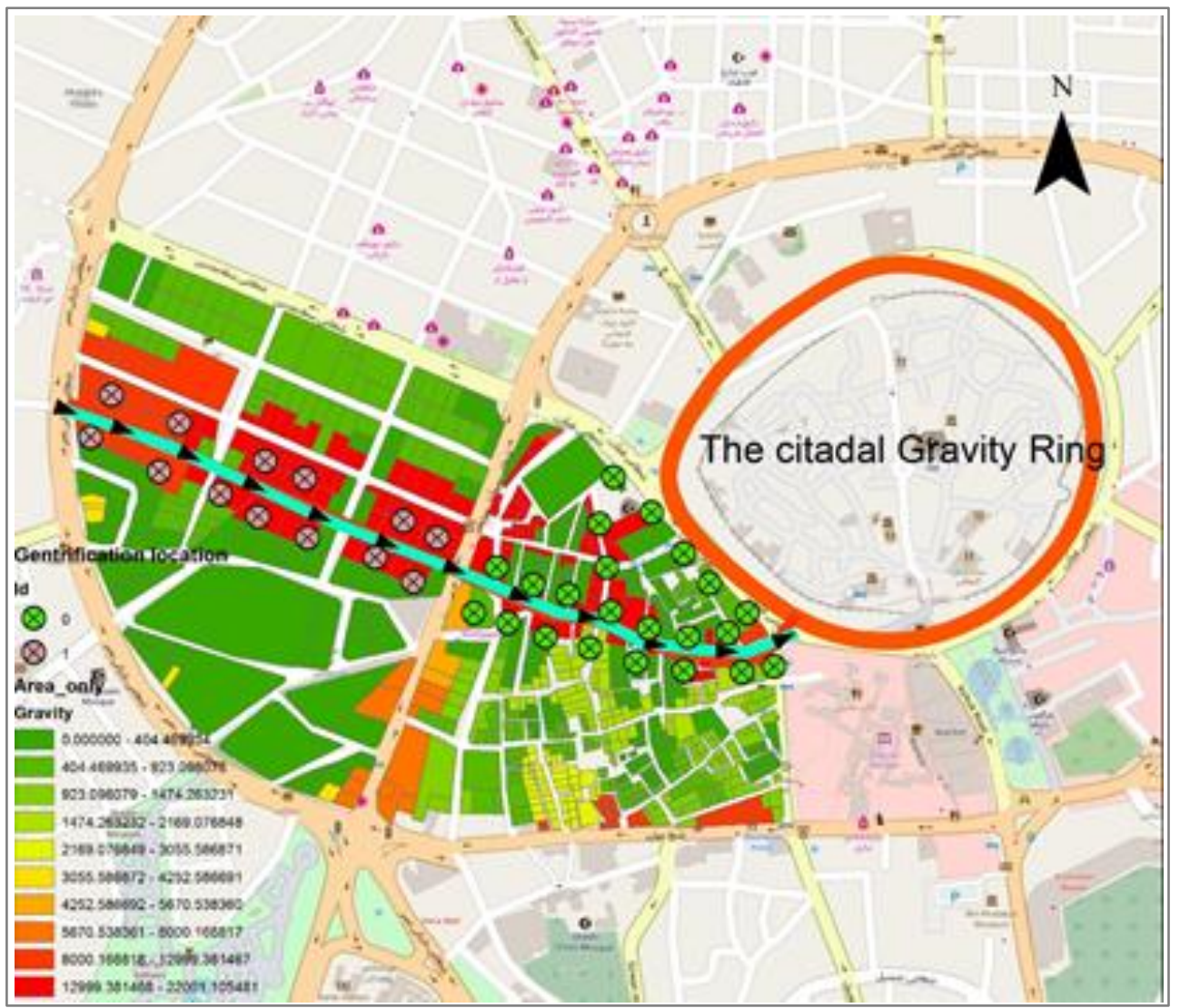

Figure 7. The development strategy in the precinct area built on plots of Gravity and accessibility

\section{Acknowledgements}

This research did not receive any specific grant from funding agencies in the public, commercial, or not-for-profit sectors.

\section{Conflict of Interests}

The Authors declare no conflict of interest.

\section{REFERENCES}

[1] M. Aziz Amen, Semiotic Based Approach for Assessing Urban Space Organization, Girne American University, Girne, 2019.

[2] A. Cocola-Gant, "Tourism gentrification," Handbook of Gentrification Studies, pp. 281-293, Edward Elgar Publishing, 2018. https://doi:10.4337/9781785361746.0002

[3] O. Kesar, R. Deželjin, M. Bienenfeld, Tourism Gentrification In The City Of Zagreb: Time For A Debate?, EconPapers, Interdisciplinary Management Research, 11, issue , p. 657-668, 2015.
[4] International Seminar Online Available: http://www.medcit ies.org/documents/10180/92710/MedCities_seminari_dubro vnik_EN_lowres.pdf/6fc7ef90-54eb-474f-b063-87d2abe67 582

[5] M. Eldaidamony and A. Shetawy, "Gentrification Indicators in the Historic City of Cairo," Procedia - Social and Behavioral Sciences, vol. 225, pp. 107-118, Jul. 2016. https://doi:10.1016/j.sbspro.2016.06.013

[6] R. Glass, Introduction: aspects of change. In: Centre for Urban Studies, University College, London: MacGibbon \& Kee, 1964.

[7] P. L. Clay, Neighborhood renewal: Middle-class resettlement and incumbent upgrading in American neighborhoods. Mass: Lexington Books, Lexington, 1979.

[8] N. Smith, "Gentrification and Capital: Practice and Ideology in Society Hill," Antipode, Vol. 11, No. 3, Pp. 24-35, Dec. 1979. https://doi:10.1111/J.1467-8330.1979.Tb00135.X

[9] N. Smith, "Gentrification and Uneven Development," Economic Geography, vol. 58, no. 2, p. 139, Apr. 1982. https://doi:10.2307/143793

[10] D. Ley, The new middle class and the remaking of the central city, Oxford University Press, Oxford, 1997.

[11] L. Lees, "Visions of 'urban renaissance': the Urban Task Force report and the Urban White Paper," Urban renaissance?, The Policy Press, Great Britain, 2003. 
https://doi:10.1332/policypress/9781861343802.003.0003

[12] S. Cameron and J. Coaffee, "Art, Gentrification and Regeneration - From Artist as Pioneer to Public Arts," European Journal of Housing Policy, vol. 5, no. 1, pp. 39-58, Apr. 2005. https://doi:10.1080/14616710500055687

[13] K. F. Gotham, Growth Machine Up-Links: Urban Renewal And The Rise And Fall Of A Pro-Growth Coalition In A U.S. City, Critical Sociology, vol. 26, no. 3, pp. 268-300, Oct. 2000. http://doi:10.1163/156916300750171918

[14] S. Zukin, The Cultures of Cities, Mass: Blackwell Publishers, Cambridge, 1995.

[15] J. Hackworth and N. Smith, The changing state of gentrification, Tijdschrift voor economische en sociale geografie, vol. 92, no. 4, pp. 464-477, Nov. 2001. https://doi:10.1111/1467-9663.00172

[16] Gotham, K, Tourism Gentrification: The Case of New Orleans' Vieux Carre (French Quarter), Urban Studies, 40 (7), 1099-1121, 2005. https://doi: 10.1080/0042098050012 0881

[17] M. García-Hernández, M. de la Calle-Vaquero, and C. Yubero, Cultural Heritage and Urban Tourism: Historic City Centres under Pressure, Sustainability, vol. 9, no. 8, p. 1346, Aug. 2017. https://doi:10.3390/su9081346

[18] B. King, "Managing urban tourism," Tourism Management, vol. 25, no. 2, pp. 290-291, Apr. 2004. doi:10.1016/s02615177(03)00085-2

[19] M. Jansen-Verbeke, "The territoriality paradigm in cultural tourism," Tourism, vol. 19, no. 1-2, Jan. 2009. https://doi:1 0.2478/v10106-009-0003-z

[20] G. Parlett, J. Fletcher, and C. Cooper, "The impact of tourism on the Old Town of Edinburgh," Tourism Management, vol. 16, no. 5, pp. 355-360, Aug. 1995. https:// doi:10.1016/0261-5177(95)00038-p

[21] J. M. Viu, J. R. Fernández, and J. S. Caralt, "The Impact of Heritage Tourism on an Urban Economy: The Case of Granada and the Alhambra," Tourism Economics, vol. 14, no. 2, pp.361-376, Jun.2008. https://doi:10.5367/00000000 8784460481

[22] H. Zhu, J. Liu, Z. Wei, W. Li, and L. Wang, Residents' Attitudes towards Sustainable Tourism Development in a Historical-Cultural Village: Influence of Perceived Impacts, Sense of Place and Tourism Development Potential, Sustainability, vol. 9, no. 1, p. 61, Jan. 2017. https://doi:10.3390/su9010061

[23] Q. Jin, H. Hu, and P. Kavan, Factors Influencing Perceived Crowding of Tourists and Sustainable Tourism Destination Management, Sustainability, vol. 8, no. 10, p. 976, Sep. 2016. https://doi:10.3390/su8100976

[24] A. J. Haley, T. Snaith, and G. Miller, The social impacts of tourism a case study of Bath, UK, Annals of Tourism Research, vol. 32, no. 3, pp. 647-668, Jul. 2005. https://doi:10.1016/j.annals.2004.10.009

[25] J. Lutz, "Urban tourism: Performance and strategies in eight European cities," Tourism Management, vol. 17, no. 4, pp. 311-312, Jun. 1996. https://doi:10.1016/0261-5177(96)870 06-3
[26] B. Neuts, "Automatic interaction detection, tourism," Encyclopedia of Tourism, pp. 1-2, 2015. https://doi:10.100 7/978-3-319-01669-6_332-1

[27] M. Popp, Positive and Negative Urban Tourist Crowding: Florence, Italy, Tourism Geographies, vol. 14, no. 1, pp. 50 72, Feb. 2012. https://doi:10.1080/14616688.2011.597421

[28] A. Savelli, "Pellegrinaggio e turismo religioso: le immagini latenti," Rivista di Scienze del Turismo - Ambiente Cultura Diritto Economia, no. 2-2014, pp. 5-22, Nov. 2014. https://doi:10.7358/rst-2014-002-save

[29] M. Gravari-Barbas and S. Guinand, Eds., Tourism and Gentrification in Contemporary Metropolises, Routledge, London Jun. 2017.

[30] J. J. Betancur, The Politics of Gentrification, Urban Affairs Review, vol. 37, no. 6, pp. 780-814, Jul. 2002. https://doi:10.1177/107874037006002

[31] J. Carpenter and L. Lees, "Gentrification in New York, London and Paris: An International Comparison," International Journal of Urban and Regional Research, vol. 19, no. 2, pp. 286-303, Jun. 1995. https://doi:10.1111/j.146 8-2427.1995.tb00505.x

[32] C. Colomb, Protest and Resistance in the Tourist City, Routledge, London, 2016. https://doi:10.4324/97813157193 06

[33] A. A. Sans and A. Q. Domínguez, 13. Unravelling Airbnb: Urban Perspectives from Barcelona, Reinventing the Local in Tourism, pp. 209-228, Channel View Publications, 2016. https://doi:10.21832/9781845415709-015

[34] Davidson, M., \& Lees, L. (2005). New-build "gentrification" and London's riverside renaissance. Environment and Planning, A, 37(7), 1165-1190. doi.org/10.1068/a3739

[35] Davidson, M., \& Lees, L. (2009). New-build gentrification: its histories, trajectories, and critical geographies. Population, Space and Place, n/a-n/a.https://doi:10.1002/ps p.584

[36] Zukin, S. (2008). Consuming Authenticity. Cultural Studies, 22(5), 724-748. https://doi:10.1080/09502380802245985

[37] Davidson, M. (2008). Spoiled mixture: where does state-led positive' gentrification end? Urban Studies, 45(12), 23852405. https://doi: 10.1177/0042098008097105

[38] S. P. Erie and M. Davis, City of Quartz: Excavating the Future in Los Angeles., Political Science Quarterly, vol. 107, no. 1, p. 177, 1992. https://doi:10.2307/2152158

[39] R. D. F. Bromley and P. K. Mackie, "Displacement and the New Spaces for Informal Trade in the Latin American City Centre," Urban Studies, vol. 46, no. 7, pp. 1485-1506, May 2009. https://doi:10.1177/0042098009104577

[40] M. Aziz Amen and D. Kuzovic, "The effect of the binary space and social interaction in creating an actual context of understanding the traditional urban space," Journal of Contemporary Urban Affairs, vol. 2, no. 2, pp. 71-77, Jan. 2018. https://doi:10.25034/ijcua.2018.3672

[41] A. Sevtsuk and M. Mekonnen, Urban network analysis. A new toolbox for ArcGIS, Revue internationale de 
géomatique, vol. 22, no. 2, pp. 287-305, Jun. 2012 https://doi:10.3166/rig.22.287-305

[42] P. Crucitti, V. Latora, and S. Porta, "Centrality measures in spatial networks of urban streets," Physical Review E, vol. 73, no. 3, Mar. 2006. https://doi:10.1103/physreve.73.0361 25
[43] A. Sevtsuk, R. Kalvo, \& O. Ekmekci, Pedestrian accessibility in grid layouts: the role of block, plot, and street dimensions, Urban Morphology 20(2):89-106, 2016.

[44] M. Mohsenin and A. Sevtsuk, The Impact of Street Properties on Cognitive Maps, Journal of Architecture and Urbanism, vol. 37, no. 4, pp. 301-309, Dec. 2013. https://doi.org/10.3846/20297955.2013.866864 